\title{
Atomistic Insight into Tetraalkylphosphonium Bis(oxalato)borate Ionic Liquid/Water Mixtures. 2. Volumetric and Dynamic Properties
}

\author{
Yong-Lei Wang, ${ }^{*},+\ddagger$ Manishkumar R. Shimpi, ${ }^{\S}$ Sten Sarman, ${ }^{\prime}$ Oleg N. Antzutkin, ${ }^{\S}$ Sergei Glavatskih, ${ }^{\ddagger}$, I \\ Lars Kloo, ${ }^{\dagger}$ and Aatto Laaksonen*,ll
${ }^{\dagger}$ Applied Physical Chemistry, Department of Chemistry and ${ }^{\ddagger}$ System and Component Design, Department of Machine Design, KTH Royal Institute of Technology, SE-100 44 Stockholm, Sweden
${ }^{\S}$ Chemistry of Interfaces, Luleå University of Technology, SE-971 87 Luleå, Sweden
"Department of Materials and Environmental Chemistry, Arrhenius Laboratory, Stockholm University, SE-106 91 Stockholm, Sweden \\ "Department of Mechanical Construction and Production, Ghent University, B-9000 Ghent, Belgium
}

ABSTRACT: Atomistic molecular dynamics simulations have been performed to investigate volumetric quantities and dynamic properties of binary trihexyltetradecylphosphonium bis(oxalato)borate $\left(\left[\mathrm{P}_{6,6,6,14}\right][\mathrm{BOB}]\right)$ ionic liquid $(\mathrm{IL}) /$ water mixtures with different water concentrations. The predicted liquid densities for typical $\left[\mathrm{P}_{6,6,6,14}\right][\mathrm{BOB}] \mathrm{IL} /$ water mixtures are consistent with available experimental data with a relative discrepancy of less than $3 \%$. The liquid densities and excess molar volumes of all studied $\left[\mathrm{P}_{6,6,6,14}\right][\mathrm{BOB}] \mathrm{IL} /$ water mixtures are characterized by concave and convex features, respectively, within full water concentration range. The dynamic properties of $\left[\mathrm{P}_{6,6,6,14}\right]$ cations, $[\mathrm{BOB}]$ anions, and water molecules are particularly analyzed through calculation of velocity autocorrelation functions, diffusion coefficients, and

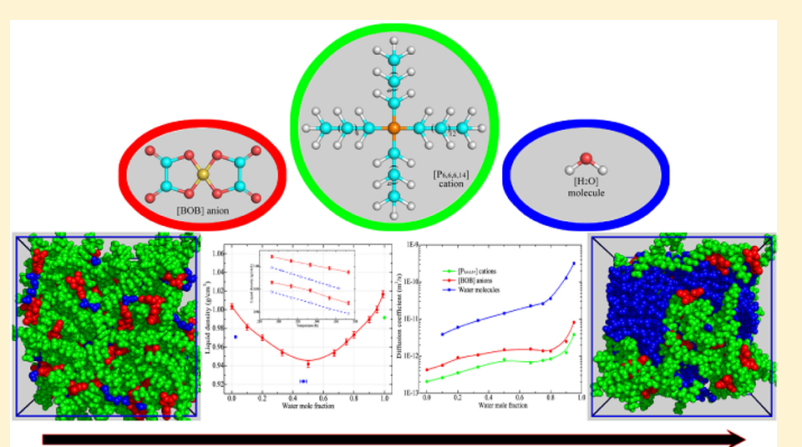

Increase in water concentration in $\left[\mathrm{P}_{6,6,6,114][\mathrm{BOB}] \mathrm{IL} / \text { water mixtures }}\right.$ reorientational autocorrelation functions and correlation times. The translational and reorientational mobilities of three species become faster upon increasing water concentration in $\left[\mathrm{P}_{6,6,6,14}\right][\mathrm{BOB}] \mathrm{IL} /$ water mixtures and present complex dynamical characteristics arising from three distinct microscopic diffusion features within the full water concentration range. The obtained striking volumetric quantities and particular dynamic properties are well correlated to microscopic liquid structural organization and distinct local ionic environment of all studied $\left[\mathrm{P}_{6,6,6,14}\right][\mathrm{BOB}] \mathrm{IL} /$ water mixtures.

\section{INTRODUCTION}

Room temperature ionic liquids (ILs) employed as attractive and recyclable solvents with tunable physicochemical properties have been and are extensively studied in laboratory frameworks and in industrial communities. ${ }^{1-5}$ During synthesis of suitable novel task-specific ILs to meet specific requirements, the presence of impurities in IL samples can strongly influence their physicochemical properties. This has motivated a significant number of theoretical and experimental studies concerning the intrinsic interplay between ionic species and impurities. ${ }^{6-23}$

Water is one of the most common "impurities" in IL samples due to ILs' intrinsic hygroscopic nature. Even those featuring hydrophobic ions can absorb significant amounts of water from the atmosphere. ${ }^{9,10,14,16-18,20-30}$ It has been experimentally observed that small traces of water can dramatically change various physicochemical properties of ILs, such as liquid densities, ${ }^{9,14,17,18,23,31,32}$ surface tensions, ${ }^{6,33}$ self-diffusion coefficients, ${ }^{9,16,17,24,26,34-39}$ viscosities and conductivities, $^{16-18,21,22,37,40-43}$ and reactivities of ionic species with respect to other solutes. ${ }^{44-47}$ In some ILs, the addition of water molecules induces gelation and narrows the electrochemical window of IL samples, likely due to electrolysis of water molecules within IL/water mixtures. ${ }^{48-50}$ Consequently, distinct discrepancies in results obtained from molecular simulations and experimental measurements are reported in the literature because of the presence of non-negligible water content in studied IL samples.

The tetraalkylphosphonium orthoborate ILs are a special category of ILs consisting of voluminous tetraalkylphosphonium cations and (chelated) orthoborate anions. These ILs present additional advantages compared with nitrogen-based ILs and can be used as alternative high-performance lubricants and lubricant additives in tribology due to their outstanding friction reducing and antiwear performance in comparison with conventional fully formulated engine oil in tribological contacts with a wide variety of materials. ${ }^{26,53}$ A previous work indicates that water is an omnipresent contaminator found in typical trihexyltetradecylphosphonium orthoborate ILs. ${ }^{26}$ The water content in freshly synthesized $\left[\mathrm{P}_{6,6,6,14}\right][\mathrm{BOB}]$ IL samples is 2.3-2.5 wt \%, and the corresponding water mole fraction is

Received: March 21, 2016

Revised: $\quad$ May 31, 2016

Published: July 7, 2016 
quite close to 0.50 . This amount of water is difficult to remove even after extensive purification. These residual water molecules in the $\left[\mathrm{P}_{6,6,6,14}\right][\mathrm{BOB}]$ IL sample might disturb heterogeneous ionic microstructures in the $\left[\mathrm{P}_{6,6,6,14}\right][\mathrm{BOB}] \mathrm{IL}$ matrix and hence lead to significant changes in ILs' other physicochemical properties, such as ILs' liquid viscosities and rheological and tribochemical quantities that are intrinsically related to their usage as lubricants in mechanical systems. Therefore, a comprehensive understanding of delicate interactions between $\left[\mathrm{P}_{6,6,6,14}\right][\mathrm{BOB}]$ ion pairs and non-negligible residual water molecules and of changes in physicochemical and microstructural properties that ILs experience upon addition of water molecules in IL samples at molecular level is essential, not only because water "impurity" is inevitably present in conventional and industrial tribological applications but also because it might provide a new opportunity to fine-tune ILs' tribochemical properties by introducing controlled amounts of solutes, like water or other small molecule solvents.

This study concerns peculiar physical properties of $\left[\mathrm{P}_{6,6,6,14}\right][\mathrm{BOB}] \mathrm{IL} /$ water mixtures with different water concentrations. The first part of this study was concentrated on microscopic liquid structural organization and the local ionic environment of $\left[\mathrm{P}_{6,6,6,14}\right][\mathrm{BOB}] \mathrm{IL} /$ water mixtures. ${ }^{54}$ Four distinct compositional regimes were identified to characterize the evolution of microscopic ionic structures of $\left[\mathrm{P}_{6,6,6,14}\right][\mathrm{BOB}]$ $\mathrm{IL} /$ water mixtures within the whole water concentration range. With a gradual increase of the water concentration, the local ionic environment and microstructures of $\left[\mathrm{P}_{6,6,6,14}\right][\mathrm{BOB}] \mathrm{IL} /$ water mixtures are characterized by solute-shared ion pairs through cation-water-anion complexes, solute-mediated ion pairs through multiple complexes, interpenetrating polar and apolar networks, and eventually loose micelle-like aggregates in a highly branched water network, as clearly shown in Figure 1.

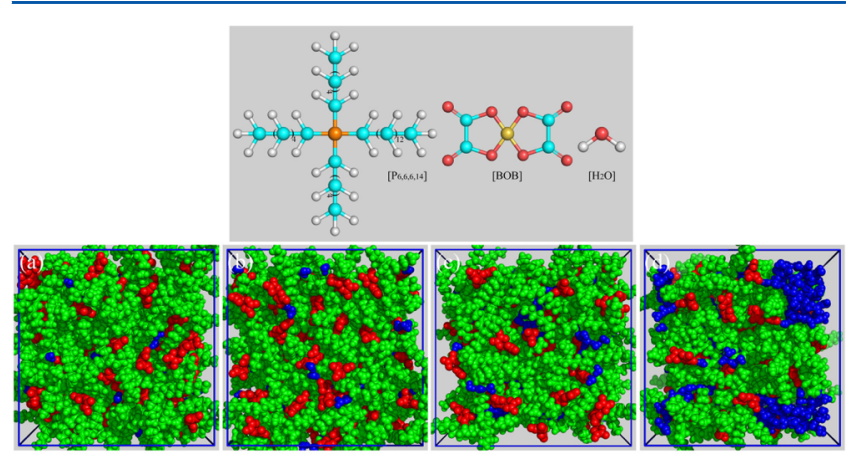

Figure 1. Schematic molecular structures of $\left[\mathrm{P}_{6,6,6,14}\right]$ cation, $[\mathrm{BOB}]$ anion, and water molecule, and representative configurations of $\left[\mathrm{P}_{6,6,6,14}\right][\mathrm{BOB}] \mathrm{IL} /$ water mixtures with water mole fractions of $x_{\text {water }}=$ (a) 0.33 , (b) 0.50 , (c) 0.80 , and (d) 0.90 . The $\left[\mathrm{P}_{6,6,6,14}\right]$ cations, [BOB] anions, and water molecules in these $\mathrm{IL} /$ water mixtures are represented by green, red, and blue beads, respectively.

Such a striking structural evolution in $\left[\mathrm{P}_{6,6,6,14}\right][\mathrm{BOB}] \mathrm{IL} /$ water mixtures is rationalized by a competition between favorable hydrogen-bonding interactions and strong electrostatic interactions between central polar segments in ionic species and by persistent dispersion interactions between hydrophobic alkyl chains of $\left[\mathrm{P}_{6,6,6,14}\right]$ cations. This work follows our previous investigation and concerns the influence of water concentration and heterogeneous microscopic liquid environments on volumetric quantities and dynamic properties of $\left[\mathrm{P}_{6,6,6,14}\right][\mathrm{BOB}] \mathrm{IL} /$ water mixtures. Atomistic simulation results of volumetric quantities described by liquid densities and excess molar volumes, and of dynamic properties characterized by typical velocity and reorientational autocorrelation functions, translational diffusion coefficients, and reorientation correlation times of representative vectors fixed in three molecular frameworks, have been systematically investigated and are discussed in detail. It is identified that dynamic properties of three species in $\left[\mathrm{P}_{6,6,6,14}\right][\mathrm{BOB}] \mathrm{IL} /$ water mixtures are quite complex and are characterized by distinct dynamical heterogeneity arising from three representative microscopic diffusion features, attributed directly to distinct spatial structural heterogeneity of $\left[\mathrm{P}_{6,6,6,14}\right][\mathrm{BOB}] \mathrm{IL} /$ water mixtures.

\section{COMPUTATIONAL AND EXPERIMENTAL METHODS}

Atomistic models of the $\left[\mathrm{P}_{6,6,6,14}\right]$ cation, $[\mathrm{BOB}]$ anion, and the adopted SPC/E water molecule are shown in Figure 1. The detailed simulation system compositions of all studied $\left[\mathrm{P}_{6,6,6,14}\right][\mathrm{BOB}] \mathrm{IL} /$ water mixtures were presented in a previous part of this study. ${ }^{54}$

Atomistic molecular dynamics simulations were performed using the M.Dynamix package ${ }^{55}$ with standard periodic boundary conditions. The equations of motion were integrated using the Tuckerman-Berne double time step algorithm ${ }^{56}$ with short and long time steps of 0.2 and $2.0 \mathrm{fs}$, respectively. The short time step was used for integrating over fast intramolecular vibrations and nonbonded interactions within $0.5 \mathrm{~nm}$ distance, whereas the long time step was used for integrating over van der Waals and electrostatic interactions, as well as dihedral angle motions, within a cutoff distance of $1.5 \mathrm{~nm}$. The electrostatic interactions between atom-centered point charges were treated using the standard Ewald summation method. All simulation systems were equilibrated for $40 \mathrm{~ns}$ in an isothermal-isobaric ensemble maintained using a NoséHoover thermostat at $333 \mathrm{~K}$ and barostat at $1 \mathrm{~atm}$ with time coupling constants of 500 and 100 fs, respectively. Further 60 ns canonical ensemble simulations were performed, and simulation trajectories were recorded at a time interval of 100 fs for statistical analysis.

The experimentally studied $\left[\mathrm{P}_{6,6,6,14}\right][\mathrm{BOB}]$ IL samples were synthesized using a slightly modified method with respect to a previous work. ${ }^{26}$ An Anton-Paar DMA $4100 \mathrm{M}$ density meter was used to determine liquid density of these synthesized $\left[\mathrm{P}_{6,6,6,14}\right][\mathrm{BOB}] \mathrm{IL}$ samples in a temperature range 293-373 K.

\section{VOLUMETRIC QUANTITIES}

Liquid Density. Volumetric quantities, such as liquid densities and excess molar volumes, of binary mixtures are complex properties because they depend not only on molecular sizes and shapes, and the nature of chemical components in binary mixtures, but also on peculiar solute-solute, solutesolvent, and solvent-solvent interactions, and on structural effects arising from interstitial accommodation due to delicate differences in molar volumes and free volumes between solution components. All these properties are particularly relevant to mixtures consisting of strongly hydrogen-bonded water molecules and IL compounds held together by strong Coulombic forces. In the current work, liquid densities of the neat $\left[\mathrm{P}_{6,6,6,14}\right][\mathrm{BOB}] \mathrm{IL}$ sample and its water mixtures within the whole water concentration range are first determined from atomistic simulations and the corresponding results are presented in Figure 2. The predicted liquid densities of 


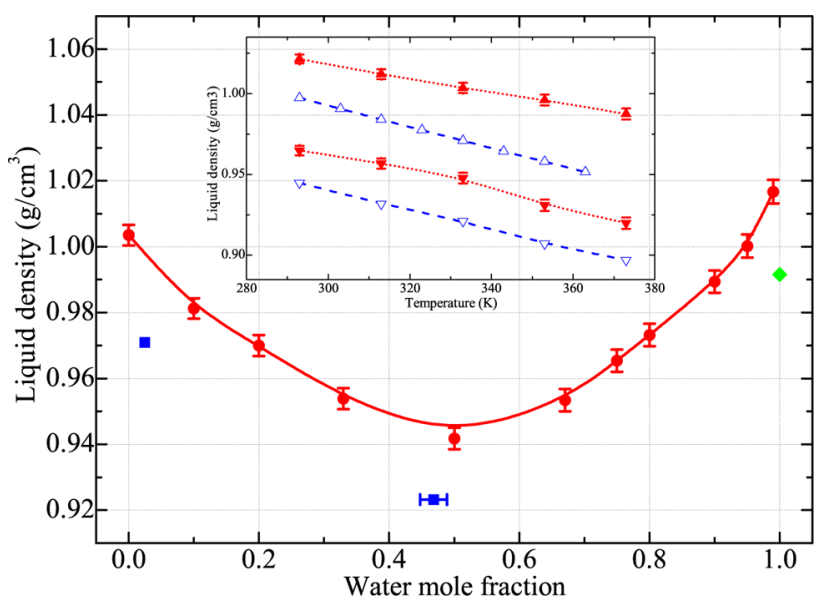

Figure 2. Liquid densities of $\left[\mathrm{P}_{6,6,6,14}\right][\mathrm{BOB}] \mathrm{IL} /$ water mixtures with different water mole fractions at $333 \mathrm{~K}$ determined from atomistic simulations (red solid circles) and from experimental measurements (blue solid squares) of two representative $\left[\mathrm{P}_{6,6,6,14}\right][\mathrm{BOB}] \mathrm{IL}$ samples with water contents of 0.06 and $2.30-2.50$ wt $\%$, respectively. The inset illustrates a comparison of liquid densities of these two representative $\left[\mathrm{P}_{6,6,6,14}\right][\mathrm{BOB}]$ IL samples with the corresponding atomistic simulation results at different temperatures. The red solid up triangles and down triangles correspond to liquid densities of neat $\left[\mathrm{P}_{6,6,6,14}\right][\mathrm{BOB}] \mathrm{IL}$ and a $\left[\mathrm{P}_{6,6,6,14}\right][\mathrm{BOB}] \mathrm{IL} /$ water mixture with a water mole fraction of $x_{\text {water }}=0.50$, respectively. The blue empty up triangles and down triangles correspond to liquid densities of two representative $\left[\mathrm{P}_{6,6,6,14}\right][\mathrm{BOB}] \mathrm{IL}$ samples with water contents of 0.06 and $2.30-2.50 \mathrm{wt} \%$, respectively. The green diamond corresponds to experimental density of water at $333 \mathrm{~K}$ taken from ref 58 .

$\left[\mathrm{P}_{6,6,6,14}\right][\mathrm{BOB}] \mathrm{IL} /$ water mixtures exhibit a concave feature within the full water concentration range, where the minimum of this concave curve corresponds to an IL/water mixture with a water mole fraction of $x_{\text {water }}=0.50$. It is notable that such a simulation system composition corresponds to a $\left[\mathrm{P}_{6,6,6,14}\right][\mathrm{BOB}] \mathrm{IL} /$ water mixture with a water content of approximately $2.60 \mathrm{wt} \%$. The atomistic simulations overestimate liquid densities of these $\left[\mathrm{P}_{6,6,6,14}\right][\mathrm{BOB}] \mathrm{IL} /$ water mixtures by approximately $3 \%$, as compared with experimental densities of two representative $\left[\mathrm{P}_{6,6,6,14}\right][\mathrm{BOB}] \mathrm{IL}$ samples with water contents of 0.06 and $2.30-2.50 \mathrm{wt} \%,{ }^{26}$ respectively. It is noteworthy that such a density overestimation is also observed for these two representative $\left[\mathrm{P}_{6,6,6,14}\right][\mathrm{BOB}] \mathrm{IL}$ samples at different temperatures, as shown in the inset of Figure 2. Such a marginal discrepancy $(\leq 3 \%)$ may be attributed either to uncertainties in experimental measurements or to defects in atomistic force field parameters used. Similar discrepancies in liquid density predictions are also observed in other tetraalkylphosphonium orthoborate ILs, as reported in our previous work. ${ }^{52}$ The observed concave feature for liquid densities of $\left[\mathrm{P}_{6,6,6,14}\right][\mathrm{BOB}] \mathrm{IL} /$ water mixtures is conceptually different from monotonically decreased liquid density trends noted for typical imidazolium-based and pyrrolidinium-based $\mathrm{IL} /$ water mixtures, $8,9,12,17,18,21,31,32,34$ and to liquid densities characterized by convex features for $\left[\mathrm{C}_{6} \mathrm{MIM}\right] /\left[\mathrm{C}_{8} \mathrm{MIM}\right] \mathrm{Cl} \mathrm{IL} /$ water mixtures ${ }^{57}$ and $\mathrm{N}$-methyl-2-pyrrolidone/water mixtures ${ }^{23}$ as the water concentration increases. This observation is rationalized by a distinct microscopic liquid structural transition in $\left[\mathrm{P}_{6,6,6,14}\right][\mathrm{BOB}] \mathrm{IL} /$ water mixtures as the water concentration increases, as discussed in the first part of this work. ${ }^{54}$

In $\left[\mathrm{P}_{6,6,6,14}\right][\mathrm{BOB}] \mathrm{IL} /$ water mixtures with water mole fractions of $x_{\text {water }}<0.50$, most of the introduced water molecules are dispersed and associated with neighboring $\left[\mathrm{P}_{6,6,6,6,14}\right][\mathrm{BOB}]$ ion pairs, leading to the local ionic environment characterized by solute-shared ion pairs through cationwater-anion complexes (panels $\mathrm{a}$ and $\mathrm{b}$ in Figure 1). An ideal condition is that one $\left[\mathrm{P}_{6,6,6,14}\right][\mathrm{BOB}]$ ion pair shares one water molecule until there is a fully saturated distribution of water molecules in all cavities between neighboring $\left[\mathrm{P}_{6,6,6,14}\right][\mathrm{BOB}]$ ion pairs, which exactly corresponds to a $\left[\mathrm{P}_{6,6,6,614}\right][\mathrm{BOB}] \mathrm{IL} /$ water mixture with a water mole fraction of $x_{\text {water }}=0.50$. However, in $\left[\mathrm{P}_{6,6,6,14}\right][\mathrm{BOB}] \mathrm{IL} /$ water mixtures with water mole fractions of $x_{\text {water }}>0.50$, water molecules tend to aggregate and form large water clusters and chain-like water structures (panel $\mathrm{c}$ in Figure 1). These large water clusters are scattered in heterogeneous IL matrices, resulting in more compact local ionic environments. Meantime, these chain-like water structures serve as water "bridges" connecting more dispersed $[\mathrm{BOB}]$ anions, as well as mediating their relative distribution and orientation in $\left[\mathrm{P}_{6,6,6,14}\right][\mathrm{BOB}] \mathrm{IL} /$ water mixtures, whereby these striking structures further considerably strengthen spatial correlations between ionic species as discussed in the first part of this work ${ }^{54}$ concerning evolution of microscopic liquid structure and local ionic organization in $\left[\mathrm{P}_{6,6,6,6,14}\right][\mathrm{BOB}] \mathrm{IL} /$ water mixtures as the water concentration increases. Both these factors contribute to an increase in liquid densities of $\left[\mathrm{P}_{6,6,6,14}\right][\mathrm{BOB}] \mathrm{IL} /$ water mixtures as the water concentration increases.

Excess Molar Volume. In addition to liquid densities, the thermodynamic nonideality of binary mixtures can be illustrated by examining related excess thermodynamic properties. ${ }^{8,16,18,21,32,34}$ Herein, we probe excess molar volume changes upon mixing neat $\mathrm{IL}$ and neat water components at different ratios. The excess molar volumes of $\left[\mathrm{P}_{6,6,6,14}\right][\mathrm{BOB}]$ $\mathrm{IL} /$ water mixtures are calculated from their respective liquid densities through the equation $V_{\text {mix }}^{\mathrm{E}}=V_{\text {mix }}-\left(x_{\mathrm{IL}} V_{\mathrm{IL}}+\right.$ $\left.x_{\text {water }} V_{\text {water }}\right)^{12,17} V_{\mathrm{IL}}, V_{\text {water }}$ and $V_{\text {mix }}$ correspond to molar volumes of pure IL and pure water components and of $\left[\mathrm{P}_{6,6,6,14}\right][\mathrm{BOB}] \mathrm{IL} /$ water mixtures, respectively. The $x_{\mathrm{IL}}$ and $x_{\text {water }}$ represent molar fractions of two pure components in the corresponding $\left[\mathrm{P}_{6,6,6,14}\right][\mathrm{BOB}] \mathrm{IL} /$ water mixtures. The quantity given in parentheses represents the molar volumes of ideal $\left[\mathrm{P}_{6,6,6,14}\right][\mathrm{BOB}] \mathrm{IL} /$ water mixtures.

The excess molar volume data $V_{\text {mix }}^{\mathrm{E}}$ of $\left[\mathrm{P}_{6,6,6,14}\right][\mathrm{BOB}] \mathrm{IL} /$ water mixtures calculated from atomistic simulations at $333 \mathrm{~K}$ are shown in Figure 3. The excess molar volumes are positive and exhibit a convex feature in the full water concentration range, indicating that $\left[\mathrm{P}_{6,6,6,6,14}\right][\mathrm{BOB}] \mathrm{IL} /$ water mixtures display a nonideal thermodynamic mixing behavior even at low water concentrations. It is estimated that a $\left[\mathrm{P}_{6,6,6,14}\right][\mathrm{BOB}] \mathrm{IL} /$ water mixture with a water mole fraction of $0.33 \leq x_{\text {water }} \leq 0.50$ has the largest excess molar volume, which is generally consistent with the observed concave liquid density trend shown in Figure 2 , as a very small deviation in liquid density calculation can result in a relatively large difference in excess molar volume. It is noteworthy that the maximum of this convex excess molar volume curve is approximately $2.5 \mathrm{~cm}^{3} / \mathrm{mol}$, which is a little larger than typical excess molar volume maxima of binary IL/ water mixtures consisting of imidazolium cations, pyridinium cations, pyrrolidinium cations, piperidinium cations, morpholinium cations, and ammonium cations coupled with different anions. ${ }^{59}$

It is well-known that the association trend of a binary mixture depends on intermolecular forces between two pure components and microscopic molecular packing structures. A 


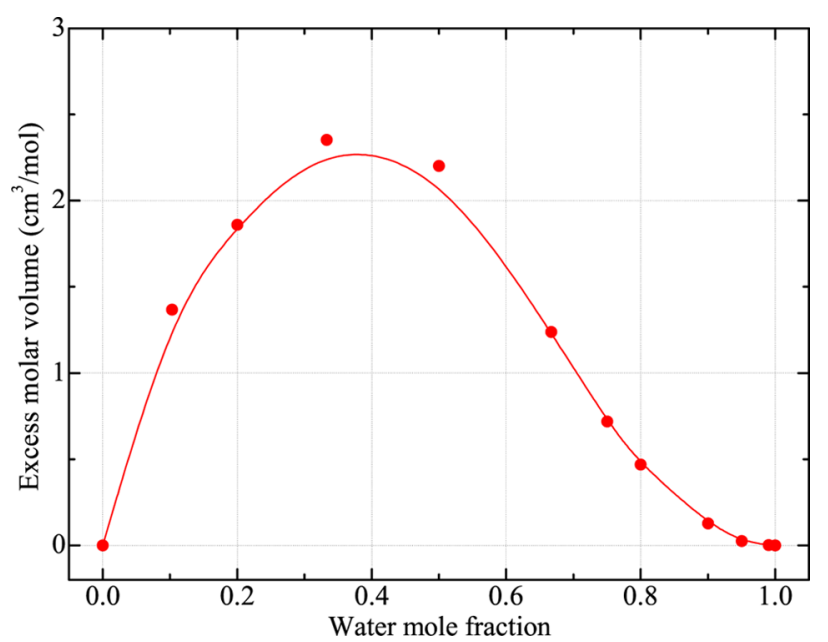

Figure 3. Excess molar volumes of $\left[\mathrm{P}_{6,6,6,14}\right][\mathrm{BOB}] \mathrm{IL} /$ water mixtures calculated from atomistic simulations at different water mole fractions at $333 \mathrm{~K}$.

positive excess molar volume is indicative of a weakening of self-association of the same type molecules, whereas a negative effect is suggested to be due to preferential association between solute and solvent molecules through particular intermolecular attractions that bring different species closer. In currently studied $\left[\mathrm{P}_{6,6,6,14}\right][\mathrm{BOB}] \mathrm{IL} /$ water mixtures, a significant positive excess molar volume indicates that the intrinsic ion-dipole interactions between water molecules and $\left[\mathrm{P}_{6,6,6,14}\right][\mathrm{BOB}]$ ion pairs are slightly weaker than interactions between liquid molecules in their respective pure components. This is astonishing, as we have observed that water molecules are strongly and specifically associated with $\left[\mathrm{P}_{6,6,6,14}\right]$ cations and [BOB] anions in microscopic ionic structural analysis due to their dual nature in hydrogen-bonding interactions. ${ }^{54} \mathrm{~A}$ possible reason might be contributed to voluminous $\left[\mathrm{P}_{6,6,6,14}\right]$ cation, which consists of two different parts: a relatively thin hydrophilic core including a central phosphorus atom and four directly connected methylene groups, and a thick hydrophobic shell consisting of the remaining part of four volume-occupying alkyl chains, and hence it presents amphiphilic surfactant-like characteristics in IL matrices. When a small amount of water is introduced into the $\left[\mathrm{P}_{6,6,6,14}\right][\mathrm{BOB}]$ IL matrix, water molecules tend to be dispersed and fit into and expand cavities between direct contact $\left[\mathrm{P}_{6,6,6,14}\right][\mathrm{BOB}]$ ion pairs, pushing hydrophobic alkyl chains together and leading to a slightly expanded simulation cell and thus to a decreased liquid density for $\left[\mathrm{P}_{6,6,6,14}\right][\mathrm{BOB}] \mathrm{IL} /$ water mixtures with water mole fractions of $x_{\text {water }}<0.50$. Energetically speaking, this observation is rationalized by a competition between favorable hydrogenbonding interactions and strong electrostatic interactions between central polar segments in ionic species and by persistent dispersion interactions between hydrophobic alkyl chains of $\left[\mathrm{P}_{6,6,6,14}\right]$ cations, as we have discussed in microscopic structural analysis in the first part of this work. ${ }^{54}$

The weakening of self-association behavior between ionic species and water molecules is a dominant feature for IL/water mixtures within the whole water concentration range, and it is obviously more important than molecular associations between ionic species and water molecules, as indicated from a generic character of positive excess molar volumes for other binary IL/ water mixtures consisting of imidazolium cations, pyridinium cations, pyrrolidinium cations, piperidinium cations, morpho- linium cations, and ammonium cations coupled with different anions. $^{59}$ From a general point of view, but not limited to currently studied $\left[\mathrm{P}_{6,6,6,14}\right][\mathrm{BOB}] \mathrm{IL} /$ water mixtures, the striking volumetric quantities reflect a complex nature of competitive interactions between cationic/anionic species and water molecules. In IL-rich mixtures, the dissociation between cations and anions caused by dispersed water molecules contributes more to the overall excess molar volume changes than does the local association between ionic species and water molecules through strong electrostatic interactions and directional hydrogen-bonding interactions. At higher water concentrations, a weakening of intermolecular self-association of hydrogen-bonded water molecules tends to dominate the phase behavior of these IL/water mixtures due to the presence of bulky (voluminous) cations and polar anions. The synergistic weakening effect of this self-association behavior contributes to the overall positive excess molar volumes for representative binary IL/water mixtures within the whole water concentration range. $^{59}$

\section{DYNAMIC PROPERTIES}

In addition to volumetric quantities and distinct microscopic ionic structures of $\left[\mathrm{P}_{6,6,6,14}\right][\mathrm{BOB}] \mathrm{IL} /$ water mixtures, we proceed to explore dynamic properties of $\left[\mathrm{P}_{6,6,6,14}\right]$ cations and [BOB] anions, as well as self-diffusivity of water molecules in different IL matrices. Atomistic simulation results of velocity autocorrelation functions, diffusion coefficients, and reorientational autocorrelation functions and correlation times of $\left[\mathrm{P}_{6,6,6,14}\right]$ cations, $[\mathrm{BOB}]$ anions, and water molecules have been calculated and will be discussed in following subsections.

Velocity Autocorrelation Function. The dynamical behavior and microscopic motion of three species in $\left[\mathrm{P}_{6,6,6,14}\right][\mathrm{BOB}] \mathrm{IL} /$ water mixtures are first examined by calculating the normalized velocity autocorrelation function (VACF), $\hat{C}_{v}(t)$, of the center-of-mass (COM) of three species from recorded simulation trajectories. The normalized VACF is defined as $\hat{C}_{v}(t)=\frac{\left\langle\mathbf{v}^{c}(0) \cdot \mathbf{v}^{c}(t)\right\rangle}{\left\langle\mathbf{v}^{c}(0) \cdot \mathbf{v}^{c}(0)\right\rangle}$, where $\mathbf{v}^{c}(t)$ are COM velocity vectors of $\left[\mathrm{P}_{6,6,6,14}\right]$ cations, $[\mathrm{BOB}]$ anions, and water molecules. The angular brackets \langle\rangle represent an ensemble average over all species of the same type within simulation system and over the entire simulation time.

Figure 4 presents the normalized VACFs of $\left[\mathrm{P}_{6,6,6,14}\right]$ cations, $[\mathrm{BOB}]$ anions, and water molecules in $\left[\mathrm{P}_{6,6,6,14}\right][\mathrm{BOB}] \mathrm{IL} /$ water mixtures with different water concentrations. A general feature is that these normalized VACFs rapidly and monotonically decay to the corresponding minimum, but such a process is weakened as the water concentration increases in $\left[\mathrm{P}_{6,6,6,14}\right][\mathrm{BOB}] \mathrm{IL} /$ water mixtures. The negative region in these normalized VACF plots indicates a rattling motion of ionic groups inside a cage formed by neighboring species. The normalized VACFs of $\left[\mathrm{P}_{6,6,6,14}\right]$ cations and $[\mathrm{BOB}]$ anions are characterized by relatively broad wells, which become less deep as the water concentration increases in $\mathrm{IL} /$ water mixtures. The minima of these normalized VACFs are located at around 0.6 and 0.4 ps for $\left[\mathrm{P}_{6,6,6,14}\right]$ cations and $[\mathrm{BOB}]$ anions, respectively, and are less dependent on the water concentration in $\left[\mathrm{P}_{6,6,6,14}\right][\mathrm{BOB}] \mathrm{IL} /$ water mixtures.

The normalized VACFs of water molecules decay much faster than those of $\left[\mathrm{P}_{6,6,6,14}\right]$ cations and $[\mathrm{BOB}]$ anions, indicating their relatively faster diffusivity in $\left[\mathrm{P}_{6,6,6,14}\right][\mathrm{BOB}]$ $\mathrm{IL} /$ water mixtures. The locations of the corresponding VACF minima gradually increase from $0.15 \mathrm{ps}$ in IL-rich mixtures to 


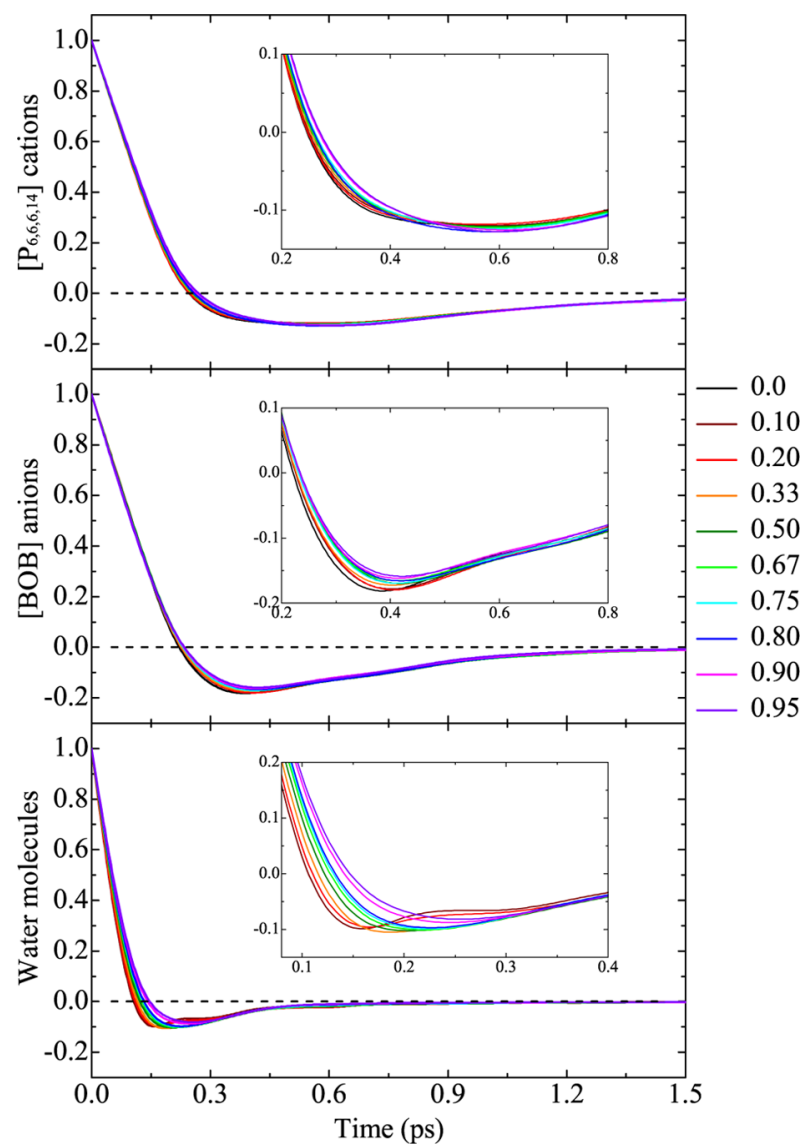

Figure 4. Normalized velocity autocorrelation functions of $\left[\mathrm{P}_{6,6,6,14}\right]$ cations, $[\mathrm{BOB}]$ anions, and water molecules in $\left[\mathrm{P}_{6,6,6,14}\right][\mathrm{BOB}] \mathrm{IL} /$ water mixtures with different water mole fractions at $333 \mathrm{~K}$. The crossover points of these normalized velocity autocorrelation functions and horizontally dashed lines are the mean collision time (short time regimes) and the velocity randomization times (long time regimes), respectively.

$0.25 \mathrm{ps}$ in water-concentrated mixtures. Upon further inspection of these VACF plots, it is observed that a considerable oscillatory feature is registered in $\left[\mathrm{P}_{6,6,6,14}\right][\mathrm{BOB}] \mathrm{IL} /$ water mixtures with less water, such as $\mathrm{IL} /$ water mixtures with water mole fractions of $x_{\text {water }}=0.10$ and 0.20 . Such an interesting VACF tendency is rationalized by a highly heterogeneous distribution of water molecules in IL-rich mixtures, in which water molecules are dispersed and associated with neighboring $\left[\mathrm{P}_{6,6,6,14}\right][\mathrm{BOB}]$ ion pairs, leading to the local ionic environments characterized by solute-shared ion pairs through cation-water-anion complexes. ${ }^{54}$

In each simulation system, the mean collision time, estimated from the first zero values in the normalized VACFs, and the velocity randomization time, estimated from the normalized VACF tails oscillating around zero, of three species follow an order of $\left[\mathrm{P}_{6,6,6,14}\right]$ cations $>[\mathrm{BOB}]$ anions $>$ water molecules. Water molecules are much smaller and lighter than $\left[\mathrm{P}_{6,6,6,14}\right]$ cations and $[\mathrm{BOB}]$ anions, and hence their normalized VACFs exhibit distinct and clear oscillations between the mean collision time and the velocity randomization time. ${ }^{60}$ In all studied $\left[\mathrm{P}_{6,6,6,14}\right][\mathrm{BOB}] \mathrm{IL} /$ water mixtures, the mean collision time, the minimum positions of these normalized VACF curves, and the velocity randomization time of three species gradually shift to longer times as the water concentration increases. All these simulation results indicate a gradual change of the local ionic coordination environment from IL-rich to waterconcentrated mixtures as more water molecules are introduced into $\left[\mathrm{P}_{6,6,6,14}\right][\mathrm{BOB}] \mathrm{IL} /$ water mixtures, akin to a distinct dynamic quantities of ionic species in binary mixtures consisting of imidazolium-based ILs and small molecule solvents (water, methanol, ethanol, etc.). ${ }^{11,20,37,38,51,61}$

Translational Diffusion. For a liquid or mixture under thermodynamic equilibrium conditions, the thermal agitation causes translational motion of liquid molecules, which is called self-diffusivity. ${ }^{60,62}$ From a molecular point of view, the selfdiffusivity of liquid molecules gives a detailed microscopic description of single-particle motion. In the present work, the single-particle dynamics of three species are further characterized by calculating their respective diffusion coefficients through integrating their respective normalized VACF plots using the Green-Kubo relationship. ${ }^{60-62}$

Due to the overall dynamic sluggishness of the neat $\left[\mathrm{P}_{6,6,6,14}\right][\mathrm{BOB}] \mathrm{IL}$ sample and some IL-rich mixtures, it is necessary to carry out relatively long atomistic simulations to reach a true diffusive regime. Therefore, one can probe true diffusive behavior of three species in a reliable way because a too short simulation usually leads to an overestimation of diffusion coefficient. ${ }^{9,17,43}$ From recorded simulation trajectories, we have verified that the dynamics of three species, either in a neat $\left[\mathrm{P}_{6,6,6,14}\right][\mathrm{BOB}]$ IL sample or in $\left[\mathrm{P}_{6,6,6,14}\right][\mathrm{BOB}] \mathrm{IL} /$ water mixtures, become diffusive after $40 \mathrm{~ns}$ of simulation time in equilibrium simulations. In the meantime, diffusion coefficients of three species are also calculated from recorded simulation trajectories through the well-known Einstein formula based on mean square displacement. ${ }^{11,17,32,60}$ In general, diffusion coefficients estimated from normalized VACF plots are consistent with those fitted from mean square displacement curves, and hence only one set of diffusion coefficient data of three species at $333 \mathrm{~K}$ is shown in Figure 5.

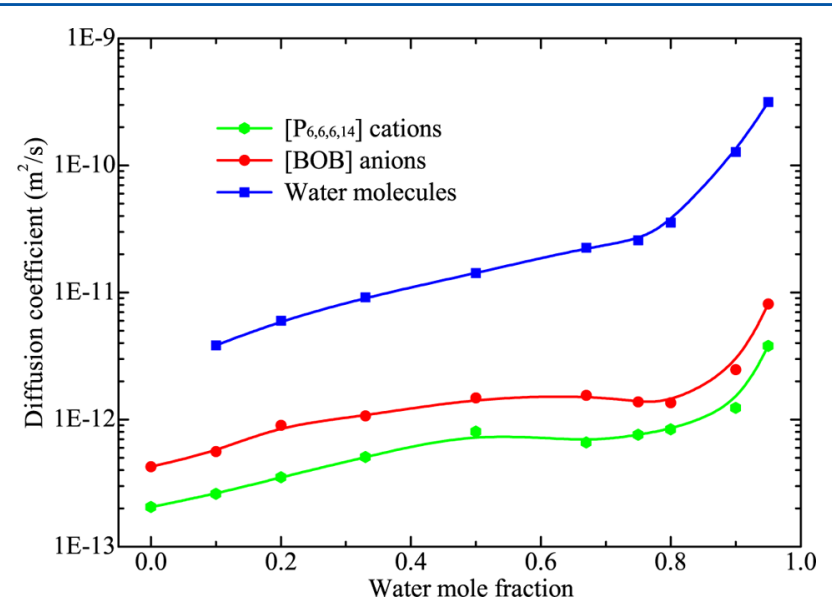

Figure 5. Diffusion coefficients of $\left[\mathrm{P}_{6,6,6,14}\right]$ cations, $[\mathrm{BOB}]$ anions, and water molecules in $\left[\mathrm{P}_{6,6,6,14}\right][\mathrm{BOB}] \mathrm{IL} /$ water mixtures with different water mole fractions at $333 \mathrm{~K}$.

In each IL/water mixture, the translational mobilities of three species follow the order water molecules $>[\mathrm{BOB}]$ anions $>$ $\left[\mathrm{P}_{6,6,6,14}\right]$ cations, and the self-diffusivity of water molecules is always 1 or 2 orders of magnitude faster than that of $\left[\mathrm{P}_{6,6,6,14}\right]$ cations and $[\mathrm{BOB}]$ anions, respectively. Similar diffusion behavior has also been observed in classic atomistic simulations and related experimental nuclear magnetic resonance spectroscopic measurements of binary mixtures consisting of 
imidazolium-based ILs and small molecule solvents (water, methanol, ethanol, etc.)..$^{11,36-38,43,61,63}$ The fast diffusion of water molecules in the present atomistic simulations is attributed to their smaller molecular size and lower molecular weight as compared to that of $\left[\mathrm{P}_{6,6,6,14}\right]$ cations and $[\mathrm{BOB}]$ anions.

Additionally, the translational diffusion coefficients of three species, generally but not linearly, increase as the water concentration increases in $\left[\mathrm{P}_{6,6,6,14}\right][\mathrm{BOB}] \mathrm{IL} /$ water mixtures. Concerning the translational mobilities of three species in all studied $\left[\mathrm{P}_{6,6,6,14}\right][\mathrm{BOB}] \mathrm{IL} /$ water mixtures with different water mole fractions, and evolution of microscopic liquid structure and local ionic organization in $\left[\mathrm{P}_{6,6,6,14}\right][\mathrm{BOB}] \mathrm{IL} /$ water mixtures discussed in the first part of this work, ${ }^{54}$ we can note that the dynamic properties of three species are complex and arise from three distinct microscopic diffusion features within the whole water concentration range.

- $\left[\mathrm{P}_{6,6,6,14}\right][\mathrm{BOB}] \mathrm{IL} /$ water mixtures with water mole fractions of $x_{\text {water }} \leq 0.50$. The diffusion coefficients of all three species exhibit an exponential increase as the water concentration increases in $\left[\mathrm{P}_{6,6,6,14}\right][\mathrm{BOB}] \mathrm{IL} /$ water mixtures. This can be attributed to distinct microscopic liquid organization and the particular local ionic environment in these IL-rich mixtures, in which three species are preferentially coupled together through solute-shared ion pairs characterized by cation-wateranion complexes. The increased molecular mobilities of three species can be rationalized by a tendency that the dispersed smaller and lighter water molecules tend to displace much heavier counterions in the first coordination shell of the ions. The diffusion of water molecules in these IL-rich mixtures is somewhat similar to the mobilities of gas molecules $\left(\mathrm{CO}_{2}, \mathrm{~N}_{2}\right.$, etc. $)$ in zeolite solid frameworks, although the cavities between neighboring ionic groups are not large enough as micropores or mesopores in zeolite solid frameworks. $^{64,65}$

- $\left[\mathrm{P}_{6,6,6,14}\right][\mathrm{BOB}] \mathrm{IL} /$ water mixtures with intermediate water mole fractions of $0.50<x_{\text {water }} \leq 0.80$. A slight downturn is observed in molecular diffusion of $\left[\mathrm{P}_{6,6,6,14}\right]$ cations and $[\mathrm{BOB}]$ anions. In these $\mathrm{IL} /$ water mixtures, large water clusters and chain-like water structures dominate water molecule distribution in IL matrices, because there is not sufficient void space to accommodate more dispersed water molecules. Water molecules prefer to form compact structures in large water clusters, leading to their overall sluggish dynamics. Additionally, chain-like water structures serve as water "bridges" connecting more ionic groups, as well as mediating their relative distribution and orientation, which further considerably strengthen spatial correlations between ionic species. Both these factors slow down selfdiffusion of $\left[\mathrm{P}_{6,6,6,14}\right]$ cations, $[\mathrm{BOB}]$ anions, and water molecules in $\left[\mathrm{P}_{6,6,6,14}\right][\mathrm{BOB}] \mathrm{IL} /$ water mixtures with intermediate water concentrations.

- $\left[\mathrm{P}_{6,6,6,14}\right][\mathrm{BOB}] \mathrm{IL} /$ water mixtures with water mole fractions of $x_{\text {water }}>0.80$. A rapid increase in diffusion coefficients of three species is observed in these waterconcentrated mixtures, attributed to a percolation of polar domains throughout the whole simulation system and formation of interpenetrating polar and apolar networks.
From a structural perspective, water has two contradictory effects on dynamic properties of $\left[\mathrm{P}_{6,6,6,14}\right]$ cationic and $[\mathrm{BOB}]$ anionic species. On the one hand, the introduction of water molecules into the $\left[\mathrm{P}_{6,6,6,14}\right][\mathrm{BOB}]$ IL matrix will increase center-of-mass distances between $\left[\mathrm{P}_{6,6,6,14}\right]$ cations and $[\mathrm{BOB}]$ anions because of the dispersed distribution of water molecules between neighboring ionic groups. The disruption of ion pair structures weakens electrostatic and hydrogen-bonding interactions between neighboring ionic groups, as well as the corresponding caging effect, leading to an improved translational diffusion of three species. On the other hand, water molecules will form a hydrogen bond network with neighboring ionic groups, which in turn will slow down translational diffusion of three species in $\left[\mathrm{P}_{6,6,6,14}\right][\mathrm{BOB}] \mathrm{IL} /$ water mixtures. These two competitive effects contribute to the particular dynamic quantities of three species in $\left[\mathrm{P}_{6,6,6,14}\right][\mathrm{BOB}] \mathrm{IL} /$ water mixtures with different water mole fractions.

Reorientational Dynamics. In addition to translational diffusion, the reorientational dynamics of three species have been investigated by examining the reorientation of representative vectors $\hat{e}$ fixed in their respective molecular frameworks to address their local dynamical characteristics. ${ }^{13,25,34,61}$ In the present study, $\left[\mathrm{P}_{6,6,6,14}\right]$ cations and water molecules are depicted by the corresponding dipolar vectors, whereas the [BOB] anionic structure is described by a unit vector pointing from the central boron atom to the geometric center of one five-membered planar ring. These vectors represent the longest geometrical axes in the corresponding species and thus are expected to have the longest reorientational relaxation times. The reorientational autocorrelation functions, represented by the first-rank Legendre polynomial $P_{1}(t)=\langle\hat{e}(t) \cdot \hat{e}(0)\rangle$ and the second-rank Legendre polynomial $P_{2}(t)=0.5\left\{3\left\langle[\hat{e}(t) \cdot \hat{e}(0)]^{2}\right\rangle\right.$ $-1\}$, respectively, are adopted to characterize peculiar reorientational dynamics of three species. ${ }^{13,31,34}$ The asymptotic decay of reorientational autocorrelation functions is approximated by a stretched exponential function $P(t)=$ $A \mathrm{e}^{-t / \tau_{0}}$, where $A$ and $\tau_{0}$ are related fitting parameters. ${ }^{34}$ The accessible quantities are reorientational correlation times $\tau_{1}$ and $\tau_{2}$, which can be estimated from the corresponding reorientational autocorrelation functions $P_{1}(t)$ and $P_{2}(t)$, respectively.

Figure 6 presents reorientational autocorrelation function $P_{1}(t)$ of representative vectors fixed in three molecular frameworks. The second-rank Legendre polynomials $P_{2}(t)$ of three representative vectors exhibit features similar to those of the corresponding $P_{1}(t)$ polynomials and are thus not shown here. The decay of reorientational correlation functions of three species follows the order $\left[\mathrm{P}_{6,6,6,14}\right]$ cations $<[\mathrm{BOB}]$ anions $<$ water molecules as the water concentration increases in $\left[\mathrm{P}_{6,6,6,14}\right][\mathrm{BOB}] \mathrm{IL} /$ water mixtures. In IL-rich mixtures, water molecules are preferentially coordinated to neighboring $\left[\mathrm{P}_{6,6,6,14}\right]$ cations and $[\mathrm{BOB}]$ anions over the entire simulation time, leading to the constrained reorientations of all three species. As the water concentration gradually increases, the microscopic liquid organization progressively loosens and results in a local ionic environment characterized by solutemediated ion pairs, facilitating reorientations of $[\mathrm{BOB}]$ anions and water molecules, and even of voluminous $\left[\mathrm{P}_{6,6,6,14}\right]$ cations.

The reorientational correlation times $\tau_{1}$ and $\tau_{2}$ of three representative vectors are presented in panel a of Figure 7 as a function of the water concentration in $\left[\mathrm{P}_{6,6,6,14}\right][\mathrm{BOB}] \mathrm{IL} /$ water mixtures. The reorientational correlation times of three species follow the order $\left[\mathrm{P}_{6,6,6,14}\right]$ cations $>[\mathrm{BOB}]$ anions $>$ water molecules as the water concentration increases, attributed 


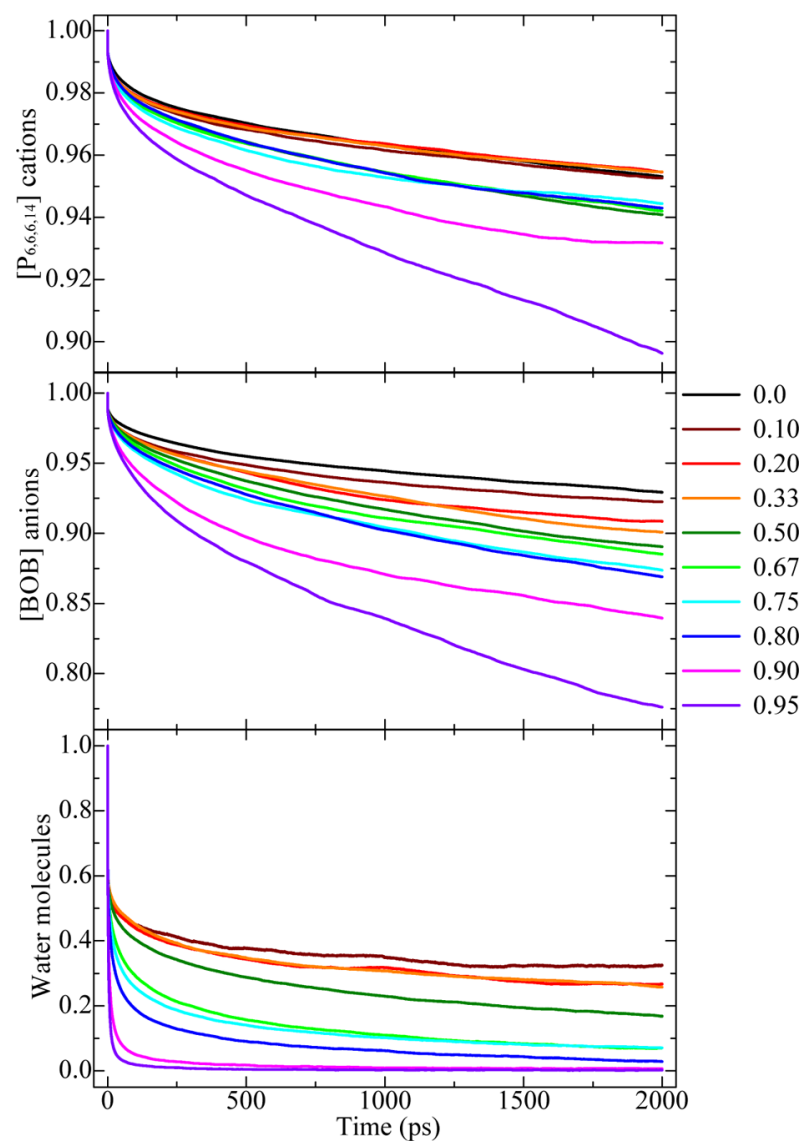

Figure 6. Reorientational autocorrelation function $P_{1}(t)$ of $\left[\mathrm{P}_{6,6,6,14}\right]$ cations, $[\mathrm{BOB}]$ anions, and water molecules in $\left[\mathrm{P}_{6,6,6,14}\right][\mathrm{BOB}] \mathrm{IL} /$ water mixtures with different water mole fractions at $333 \mathrm{~K}$.

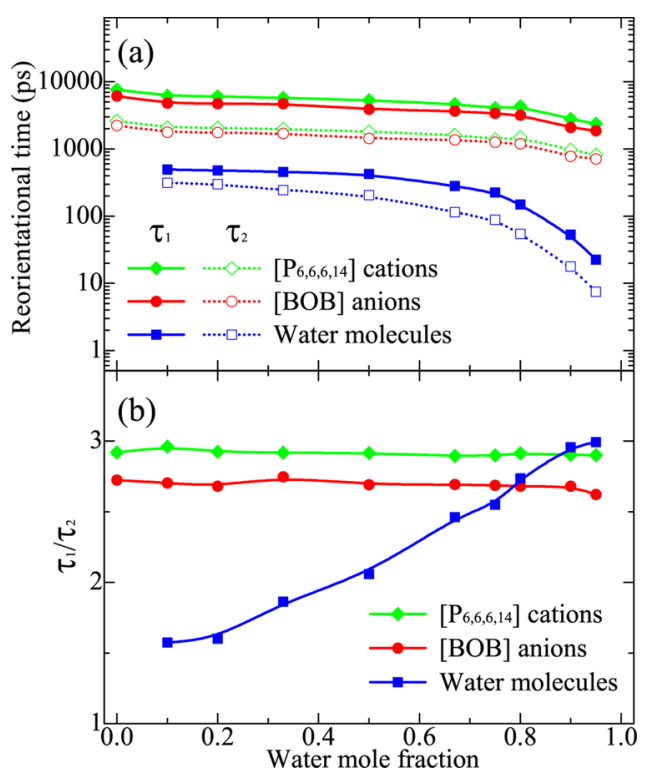

Figure 7. Reorientational correlation times $\tau_{1}$ and $\tau_{2}$ (a), and the values of $\tau_{1} / \tau_{2}$ (b) for the representative vectors fixed in three molecular frameworks in $\left[\mathrm{P}_{6,6,6,14}\right][\mathrm{BOB}] \mathrm{IL} /$ water mixtures with different water mole fractions at $333 \mathrm{~K}$.

to the respective molecular sizes and molecular weights of three species. Additionally, all these reorientational correlation times, estimated from either the first- or the second-rank Legendre polynomials, decrease progressively in IL/water mixtures with water mole fractions of $x_{\text {water }} \leq 0.80$ and sharply in IL/water mixtures with water mole fractions of $x_{\text {water }}>0.80$, respectively. This is expected, as highly mobile water molecules tend to increase mobilities of $\left[\mathrm{P}_{6,6,6,14}\right]$ cations and $[\mathrm{BOB}]$ anions due to their strong coordinations in all studied $\mathrm{IL} /$ water mixtures, and this is compatible with the increased translational diffusion coefficients of three species shown in previous subsection.

Concerning the reorientational anisotropy of three representative vectors, the ratio of $\tau_{1}$ over $\tau_{2}$ is calculated and presented in panel $\mathrm{b}$ of Figure 7 . The value of $\tau_{1} / \tau_{2}$ is expected to be 3 for completely isotropic reorientations of representative vectors, and much smaller than 3 for vector reorientations restricted in a cone or a planar surface. ${ }^{39,62}$ It is shown that all values of $\tau_{1} / \tau_{2}$ are quite close to 3 for $\left[\mathrm{P}_{6,6,6,14}\right]$ cations and [BOB] anions, indicating a relatively isotropic reorientation of both $\left[\mathrm{P}_{6,6,6,14}\right]$ cations and $[\mathrm{BOB}]$ anions in all studied $\mathrm{IL} /$ water mixtures. The molecular geometries of $\left[\mathrm{P}_{6,6,6,14}\right]$ cations and [BOB] anions characterized by $C_{3 v}$ and $D_{2 d}$ symmetries, and their relative ionic sizes, contribute to a marginal difference in their respective values of $\tau_{1} / \tau_{2}$.

However, the computational results of $\tau_{1} / \tau_{2}$ for water molecules exhibit a pronounced dependence on the water concentration in $\left[\mathrm{P}_{6,6,6,14}\right][\mathrm{BOB}] \mathrm{IL} /$ water mixtures. In IL-rich mixtures, water molecules are dispersed and coordinated to neighboring $\left[\mathrm{P}_{6,6,6,14}\right]$ cations and $[\mathrm{BOB}]$ anions through distinct cation-water-anion complexes. On the one hand, oxygen atoms in water molecules are constrained to hydrogen atoms (labeled as HP atoms) in methylene groups that are directly connected to central phosphorus atoms in $\left[\mathrm{P}_{6,6,6,14}\right]$ cations. On the other hand, hydrogen atoms (at least one in each water molecule) in water molecules are particularly concentrated along hydrophilic $\mathrm{C}=\mathrm{O}$ vectors fixed in the [BOB] anionic framework. Such restricted distribution and orientation of oxygen and hydrogen atoms lead to a constrained dipolar reorientation of water molecules on a cone surface. As the water concentration increases, dispersed water molecules tend to aggregate and form large water clusters, and thus reorientation of water dipolar vectors becomes less constricted. In water-concentrated mixtures, the values of $\tau_{1} / \tau_{2}$ approach 3 , indicating an isotropic reorientation of water molecules as the local microscopic water structures more and more resemble that in bulk liquid water.

\section{SUMMARY AND CONCLUSION}

In the present work, we have computationally investigated the effects of water concentration on volumetric quantities and dynamic properties of binary $\left[\mathrm{P}_{6,6,6,14}\right][\mathrm{BOB}] \mathrm{IL} /$ water mixtures with appreciable atomistic detail. The volumetric quantities of $\left[\mathrm{P}_{6,6,6,14}\right][\mathrm{BOB}] \mathrm{IL} /$ water mixtures, including liquid densities and excess molar volumes, have been discussed in detail. The liquid densities of $\left[\mathrm{P}_{6,6,6,14}\right][\mathrm{BOB}] \mathrm{IL} /$ water mixtures exhibit a concave feature as the water concentration increases. The mixing of pure $\left[\mathrm{P}_{6,6,6,14}\right][\mathrm{BOB}]$ IL and pure water component illustrates a thermodynamic nonideality at different mixing ratios, as suggested from a convex character of excess molar volumes of $\left[\mathrm{P}_{6,6,6,14}\right][\mathrm{BOB}] \mathrm{IL} /$ water mixtures, attributed to distinct intermolecular interactions between two pure components leading to varied microscopic molecular packing structures.

The dynamic properties of $\left[\mathrm{P}_{6,6,6,14}\right]$ cations, $[\mathrm{BOB}]$ anions, and water molecules are particularly analyzed through velocity autocorrelation functions, diffusion coefficients, and reorienta- 
tional autocorrelation functions and correlation times. Distinct translational behavior of three species, and striking reorientational autocorrelation functions and correlation times of representative vectors fixed in three molecular frameworks are observed in $\left[\mathrm{P}_{6,6,6,14}\right][\mathrm{BOB}] \mathrm{IL} /$ water mixtures with different water concentrations. Molecular mobilities of three species become faster as the water concentration increases in $\left[\mathrm{P}_{6,6,6,14}\right][\mathrm{BOB}] \mathrm{IL} /$ water mixtures. The dependence of diffusion coefficients of three species on the water concentration presents complex characteristics and three distinct microscopic diffusion features are identified within the whole water concentration range.

The remarkable volumetric quantities and particular dynamic properties of $\left[\mathrm{P}_{6,6,6,14}\right][\mathrm{BOB}] \mathrm{IL} /$ water mixtures are well correlated to distinct microscopic liquid structural organization and the local ionic environment of $\left[\mathrm{P}_{6,6,6,14}\right][\mathrm{BOB}] \mathrm{IL} /$ water mixtures, as discussed in the first part of this work. ${ }^{54}$ Both structural and dynamical heterogeneities of $\left[\mathrm{P}_{6,6,6,14}\right][\mathrm{BOB}] \mathrm{IL} /$ water mixtures are essentially important for understanding their functional performance in large-scale industrial applications, for example, as lubricants and lubricant additives in tribology and as alternative solvents and electrolytes in electrochemical devices.

\section{AUTHOR INFORMATION}

\section{Corresponding Authors}

*Y.-L. Wang. E-mail: wangyonl@gmail.com. Phone: 00468 162372. Fax: 00468152187.

*A. Laaksonen. E-mail: aatto.laaksonen@mmk.su.se. Phone: 00468 162372. Fax: 00468152187.

\section{Notes}

The authors declare no competing financial interest.

\section{ACKNOWLEDGMENTS}

We gratefully acknowledge financial support from Knut and Alice Wallenberg Foundation (Project number KAW 2012.0078) and Swedish Research Council (Project number 2013-5171). All computer simulations were performed using computational resources provided by the Swedish National Infrastructure for Computing (SNIC) at PDC, HPC2N, and NSC.

\section{REFERENCES}

(1) Greaves, T. L.; Drummond, C. J. Protic Ionic Liquids: Properties and Applications. Chem. Rev. 2008, 108, 206-237.

(2) Plechkova, N. V.; Seddon, K. R. Applications of Ionic Liquids in the Chemical Industry. Chem. Soc. Rev. 2008, 37, 123-150.

(3) Weingärtner, H. Understanding Ionic Liquids at the Molecular Level: Facts, Problems, and Controversies. Angew. Chem., Int. Ed. 2008, 47, 654-670.

(4) Maginn, E. J. Molecular Simulation of Ionic Liquids: Current Status and Future Opportunities. J. Phys.: Condens. Matter 2009, 21, 373101.

(5) Hallett, J. P.; Welton, T. Room-Temperature Ionic Liquids: Solvents for Synthesis and Catalysis. 2. Chem. Rev. 2011, 111, 35083576.

(6) Bowers, J.; Butts, C. P.; Martin, P. J.; Vergara-Gutierrez, M. C.; Heenan, R. K. Aggregation Behavior of Aqueous Solutions of Ionic Liquids. Langmuir 2004, 20, 2191-2198.

(7) Deetlefs, M.; Hardacre, C.; Nieuwenhuyzen, M.; Sheppard, O.; Soper, A. K. Structure of Ionic Liquid-Benzene Mixtures. J. Phys. Chem. B 2005, 109, 1593-1598.

(8) Huo, Y.; Xia, S.; Ma, P. Densities of Ionic Liquids, 1-Butyl-3methylimidazolium Hexafluorophosphate and 1-Butyl-3-methylimida- zolium Tetrafluoroborate, with Benzene, Acetonitrile, and 1-Propanol at $\mathrm{T}=(293.15$ to 343.15) K. J. Chem. Eng. Data 2007, 52, 2077-2082. (9) Moreno, M.; Castiglione, F.; Mele, A.; Pasqui, C.; Raos, G. Interaction of Water with the Model Ionic Liquid [BMIM] $\left[\mathrm{BF}_{4}\right]$ : Molecular Dynamics Simulations and Comparison with NMR Data. J. Phys. Chem. B 2008, 112, 7826-7836.

(10) Ficke, L. E.; Brennecke, J. F. Interactions of Ionic Liquids and Water. J. Phys. Chem. B 2010, 114, 10496-10501.

(11) Méndez-Morales, T.; Carrete, J.; García, M.; Cabeza, O.; Gallego, L. J.; Varela, L. M. Dynamical Properties of Alcohol + 1Hexyl-3-methylimidazolium Ionic Liquid Mixtures: A Computer Simulation Study. J. Phys. Chem. B 2011, 115, 15313-15322.

(12) Méndez-Morales, T.; Carrete, J.; Cabeza, O.; Gallego, L. J.; Varela, L. M. Molecular Dynamics Simulations of the Structural and Thermodynamic Properties of Imidazolium-Based Ionic Liquid Mixtures. J. Phys. Chem. B 2011, 115, 11170-11182.

(13) Zahn, S.; Wendler, K.; Delle Site, L.; Kirchner, B. Depolarization of Water in Protic Ionic Liquids. Phys. Chem. Chem. Phys. 2011, 13, 15083-15093.

(14) Brehm, M.; Weber, H.; Pensado, A. S.; Stark, A.; Kirchner, B. Proton Transfer and Polarity Changes in Ionic Liquid-Water Mixtures: A Perspective on Hydrogen Bonds from Ab Initio Molecular Dynamics at the Example of 1-Ethyl-3-methylimidazolium Acetate Water Mixtures Part 1. Phys. Chem. Chem. Phys. 2012, 14, 5030-5044.

(15) Hayes, R.; Imberti, S.; Warr, G. G.; Atkin, R. How Water Dissolves in Protic Ionic Liquids. Angew. Chem., Int. Ed. 2012, 51, $7468-7471$.

(16) Shi, W.; Damodaran, K.; Nulwala, H. B.; Luebke, D. R Theoretical and Experimental Studies of Water Interaction in Acetate Based Ionic Liquids. Phys. Chem. Chem. Phys. 2012, 14, 15897-15908.

(17) Zhong, X.; Fan, Z.; Liu, Z.; Cao, D. Local Structure Evolution and its Connection to Thermodynamic and Transport Properties of 1Butyl-3-methylimidazolium Tetrafluoroborate and Water Mixtures by Molecular Dynamics Simulations. J. Phys. Chem. B 2012, 116, 32493263.

(18) Borodin, O.; Henderson, W. A.; Fox, E. T.; Berman, M.; Gobet, M.; Greenbaum, S. Influence of Solvent on Ion Aggregation and Transport in $\mathrm{PY}_{15}$ TFSI Ionic Liquid-Aprotic Solvent Mixtures. J. Phys. Chem. B 2013, 117, 10581-10588.

(19) D'Angelo, P.; Zitolo, A.; Aquilanti, G.; Migliorati, V. Using a Combined Theoretical and Experimental Approach to Understand the Structure and Dynamics of Imidazolium-Based Ionic Liquids/Water Mixtures. 2. EXAFS Spectroscopy. J. Phys. Chem. B 2013, 117, 1251612524.

(20) Terranova, Z. L.; Corcelli, S. A. Molecular Dynamics Investigation of the Vibrational Spectroscopy of Isolated Water in an Ionic Liquid. J. Phys. Chem. B 2014, 118, 8264-8272.

(21) Umapathi, R.; Attri, P.; Venkatesu, P. Thermophysical Properties of Aqueous Solution of Ammonium-Based Ionic Liquids. J. Phys. Chem. B 2014, 118, 5971-5982.

(22) Usula, M.; Porcedda, S.; Mocci, F.; Gontrani, L.; Caminiti, R.; Marincola, F. C. NMR, Calorimetry, and Computational Studies of Aqueous Solutions of N-methyl-2-pyrrolidone. J. Phys. Chem. B 2014, $118,10493-10502$.

(23) Usula, M.; Mocci, F.; Marincola, F. C.; Porcedda, S.; Gontrani, L.; Caminiti, R. The Structural Organization of N-methyl-2pyrrolidone + Water Mixtures: A Densitometry, X-ray Diffraction, and Molecular Dynamics Study. J. Chem. Phys. 2014, 140, 124503.

(24) Rollet, A.-L.; Porion, P.; Vaultier, M.; Billard, I.; Deschamps, M.; Bessada, C.; Jouvensal, L. Anomalous Diffusion of Water in [BMIM][TFSI] Room-Temperature Ionic Liquid. J. Phys. Chem. B 2007, 111, 11888-11891.

(25) Spickermann, C.; Thar, J.; Lehmann, S. B. C.; Zahn, S.; Hunger, J.; Buchner, R.; Hunt, P. A.; Welton, T.; Kirchner, B. Why Are Ionic Liquid Ions Mainly Associated in Water? A Car-Parrinello Study of 1Ethyl-3-methyl-imidazolium Chloride Water Mixture. J. Chem. Phys. 2008, 129, 104505.

(26) Shah, F. U.; Glavatskih, S.; MacFarlane, D. R.; Somers, A.; Forsyth, M.; Antzutkin, O. N. Novel Halogen-Free Chelated 
Orthoborate-Phosphonium Ionic Liquids: Synthesis and Tribophysical Properties. Phys. Chem. Chem. Phys. 2011, 13, 12865-12873.

(27) Dong, K.; Cao, Y.; Yang, Q.; Zhang, S.; Xing, H.; Ren, Q. Role of Hydrogen Bonds in Ionic-Liquid-Mediated Extraction of Natural Bioactive Homologues. Ind. Eng. Chem. Res. 2012, 51, 5299-5308.

(28) Filippov, A.; Shah, F. U.; Taher, M.; Glavatskih, S.; Antzutkin, O. N. NMR Self-Diffusion Study of a Phosphonium Bis(mandelato)borate Ionic Liquid. Phys. Chem. Chem. Phys. 2013, 15, 9281-9287.

(29) Khan, I.; Taha, M.; Ribeiro-Claro, P.; Pinho, S. P.; Coutinho, J. A. P. Effect of the Cation on the Interactions between Alkyl Methyl Imidazolium Chloride Ionic Liquids and Water. J. Phys. Chem. B 2014, 118, 10503-10514.

(30) Taher, M.; Shah, F. U.; Filippov, A.; de Baets, P.; Glavatskih, S.; Antzutkin, O. N. Halogen-Free Pyrrolidinium Bis(mandelato)borate Ionic Liquids: Some Physicochemical Properties and Lubrication Performance as Additives to Polyethylene Glycol. RSC Adv. 2014, 4, 30617-30623.

(31) Feng, S.; Voth, G. A. Molecular Dynamics Simulations of Imidazolium-Based Ionic Liquid/Water Mixtures: Alkyl Side Chain Length and Anion Effects. Fluid Phase Equilib. 2010, 294, 148-156.

(32) Niazi, A. A.; Rabideau, B. D.; Ismail, A. E. Effects of Water Concentration on the Structural and Diffusion Properties of Imidazolium-Based Ionic Liquid-Water Mixtures. J. Phys. Chem. B 2013, 117, 1378-1388.

(33) Wang, J.; Wang, H.; Zhang, S.; Zhang, H.; Zhao, Y. Conductivities, Volumes, Fluorescence, and Aggregation Behavior of Ionic Liquids $\left[\mathrm{C}_{4} \mathrm{mim}\right]\left[\mathrm{BF}_{4}\right]$ and $\left[\mathrm{C}_{n} \mathrm{mim}\right] \mathrm{Br}(\mathrm{n}=4,6,8,10,12)$ in Aqueous Solutions. J. Phys. Chem. B 2007, 111, 6181-6188.

(34) Hanke, C. G.; Lynden-Bell, R. M. A Simulation Study of WaterDialkylimidazolium Ionic Liquid Mixtures. J. Phys. Chem. B 2003, 107, 10873-10878.

(35) Jiang, W.; Wang, Y.; Voth, G. A. Molecular Dynamics Simulation of Nanostructural Organization in Ionic Liquid/Water Mixtures. J. Phys. Chem. B 2007, 111, 4812-4818.

(36) Porter, A. R.; Liem, S. Y.; Popelier, P. L. A. Room Temperature Ionic Liquids Containing Low Water Concentrations - A Molecular Dynamics Study. Phys. Chem. Chem. Phys. 2008, 10, 4240-4248.

(37) Spohr, H. V.; Patey, G. N. The Influence of Water on the Structural and Transport Properties of Model Ionic Liquids. J. Chem. Phys. 2010, 132, 234510.

(38) Méndez-Morales, T.; Carrete, J.; Cabeza, O.; Gallego, L. J.; Varela, L. M. Molecular Dynamics Simulation of the Structure and Dynamics of Water - 1-Alkyl-3-methylimidazolium Ionic Liquid Mixtures. J. Phys. Chem. B 2011, 115, 6995-7008.

(39) Migliorati, V.; Zitolo, A.; D'Angelo, P. Using a Combined Theoretical and Experimental Approach to Understand the Structure and Dynamics of Imidazolium-Based Ionic Liquids/Water Mixtures. 1. MD Simulations. J. Phys. Chem. B 2013, 117, 12505-12515.

(40) Xu, H.; Zhao, D.; Xu, P.; Liu, F.; Gao, G. Conductivity and Viscosity of 1-Allyl-3-methyl-imidazolium Chloride + Water and + Ethanol from 293.15 to 333.15 K. J. Chem. Eng. Data 2005, 50, 133135.

(41) Widegren, J. A.; Laesecke, A.; Magee, J. W. The Effect of Dissolved Water on the Viscosities of Hydrophobic Room-Temperature Ionic Liquids. Chem. Commun. 2005, 1610-1612.

(42) Gómez, E.; González, B.; Domínguez, Á.; Tojo, E.; Tojo, J. Dynamic Viscosities of a Series of 1-Alkyl-3-methylimidazolium Chloride Ionic Liquids and Their Binary Mixtures with Water at Several Temperatures. J. Chem. Eng. Data 2006, 51, 696-701.

(43) Kelkar, M. S.; Maginn, E. J. Effect of Temperature and Water Content on the Shear Viscosity of the Ionic Liquid 1-Ethyl-3methylimidazolium Bis(trifluoromethanesulfonyl)imide as Studied by Atomistic Simulations. J. Phys. Chem. B 2007, 111, 4867-4876.

(44) Mele, A.; Tran, C. D.; De Paoli Lacerda, S. H. The Structure of a Room-Temperature Ionic Liquid with and without Trace Amounts of Water: The Role of $\mathrm{C}-\mathrm{H} \cdots \mathrm{O}$ and $\mathrm{C}-\mathrm{H} \cdots \mathrm{F}$ Interactions in 1-n-Butyl3-methylimidazolium Tetrafluoroborate. Angew. Chem., Int. Ed. 2003, 42, 4364-4366.
(45) Kim, D. W.; Hong, D. J.; Seo, J. W.; Kim, H. S.; Kim, H. K.; Song, C. E.; Chi, D. Y. Hydroxylation of Alkyl Halides with Water in Ionic Liquid: Significantly Enhanced Nucleophilicity of Water. J. Org. Chem. 2004, 69, 3186-3189.

(46) Wang, Y.; Li, H.; Han, S. A Theoretical Investigation of the Interactions Between Water Molecules and Ionic Liquids. J. Phys. Chem. B 2006, 110, 24646-24651.

(47) Yasaka, Y.; Wakai, C.; Matubayasi, N.; Nakahara, M. Slowdown of $\mathrm{H} / \mathrm{D}$ Exchange Reaction Rate and Water Dynamics in Ionic Liquids: Deactivation of Solitary Water Solvated by Small Anions in 1Butyl-3-methyl-imidazolium Chloride. J. Phys. Chem. A 2007, 111, 541-543.

(48) Firestone, M. A.; Dzielawa, J. A.; Zapol, P.; Curtiss, L. A.; Seifert, S.; Dietz, M. L. Lyotropic Liquid-Crystalline Gel Formation in a Room-Temperature Ionic Liquid. Langmuir 2002, 18, 7258-7260.

(49) Widegren, J. A.; Saurer, E. M.; Marsh, K. N.; Magee, J. W. Electrolytic Conductivity of Four Imidazolium-Based Room-Temperature Ionic Liquids and the Effect of a Water Impurity. J. Chem. Thermodyn. 2005, 37, 569-575.

(50) O'Mahony, A. M.; Silvester, D. S.; Aldous, L.; Hardacre, C.; Compton, R. G. Effect of Water on the Electrochemical Window and Potential Limits of Room-Temperature Ionic Liquids. J. Chem. Eng. Data 2008, 53, 2884-2891.

(51) Docampo-Álvarez, B.; Gómez-González, V.; Méndez-Morales, T.; Carrete, J.; Rodríguez, J. R.; Cabeza, Ó.; Gallego, L. J.; Varela, L. M. Mixtures of Protic Ionic Liquids and Molecular Cosolvents: A Molecular Dynamics Simulation. J. Chem. Phys. 2014, 140, 214502.

(52) Wang, Y.-L.; Shah, F. U.; Glavatskih, S.; Antzutkin, O. N.; Laaksonen, A. Atomistic Insight into Orthoborate-Based Ionic Liquids: Force Field Development and Evaluation. J. Phys. Chem. B 2014, 118, $8711-8723$

(53) Shah, F. U.; Glavatskih, S.; Antzutkin, O. N. Boron in tribology: From borates to ionic liquids. Tribol. Lett. 2013, 51, 281-301.

(54) Wang, Y.-L.; Sarman, S.; Glavatskih, S.; Antzutkin, O. N.; Rutland, M. W.; Laaksonen, A. Atomistic Insight into Tetraalkylphosphonium-Bis(oxalato) borate Ionic Liquid/Water Mixtures. I. Local Microscopic Structure. J. Phys. Chem. B 2015, 119, 5251-5264.

(55) Lyubartsev, A. P.; Laaksonen, A. M. DynaMix-A Scalable Portable Parallel MD Simulation Package for Arbitrary Molecular Mixtures. Comput. Phys. Commun. 2000, 128, 565-589.

(56) Tuckerman, M.; Berne, B. J.; Martyna, G. J. Reversible Multiple Time Scale Molecular Dynamics. J. Chem. Phys. 1992, 97, 1990.

(57) Sastry, N. V.; Vaghela, N. M.; Macwan, P. M. Densities, excess molar and partial molar volumes for water + 1-butyl-or, 1-hexyl-or, 1octyl-3-methylimidazolium halide room temperature ionic liquids at $\mathrm{T}$ $=(298.15$ and 308.15) K. J. Mol. Liq. 2013, 180, 12-18.

(58) Wagner, W.; Pruß, A. The IAPWS formulation 1995 for the thermodynamic properties of ordinary water substance for general and scientific use. J. Phys. Chem. Ref. Data 2002, 31, 387-535.

(59) Bahadur, I.; Letcher, T. M.; Singh, S.; Redhi, G. G.; Venkatesu, P.; Ramjugernath, D. Excess molar volumes of binary mixtures (an ionic liquid+ water): A review. J. Chem. Thermodyn. 2015, 82, 34-46.

(60) Wang, Y.-L.; Lu, Z.-Y.; Laaksonen, A. Heterogeneous Dynamics of Ionic Liquid in Confined Films with Varied Film Thickness. Phys. Chem. Chem. Phys. 2014, 16, 20731-20740.

(61) Maerzke, K. A.; Goff, G. S.; Runde, W. H.; Schneider, W. F.; Maginn, E. J. Structure and Dynamics of Uranyl(VI) and Plutonyl(VI) Cations in Ionic Liquid/Water Mixtures via Molecular Dynamics Simulations. J. Phys. Chem. B 2013, 117, 10852-10868.

(62) Liu, H.; Maginn, E. A Molecular Dynamics Investigation of the Structural and Dynamic Properties of the Ionic Liquid 1-n-Butyl-3methylimidazolium Bis(trifluoromethanesulfonyl)imide. J. Chem. Phys. 2011, 135, 124507.

(63) Raabe, G.; Köhler, J. Thermodynamical and Structural Properties of Binary Mixtures of Imidazolium Chloride Ionic Liquids and Alcohols from Molecular Simulation. J. Chem. Phys. 2008, 129, 144503. 
(64) Mace, A.; Hedin, N.; Laaksonen, A. Role of Ion Mobility in Molecular Sieving of $\mathrm{CO}_{2}$ over $\mathrm{N}_{2}$ with Zeolite NaKA. J. Phys. Chem. C 2013, 117, 24259-24267.

(65) Mace, A.; Laasonen, K.; Laaksonen, A. Free Energy Barriers for $\mathrm{CO}_{2}$ and $\mathrm{N}_{2}$ in Zeolite NaKA: An Ab initio Molecular Dynamics Approach. Phys. Chem. Chem. Phys. 2014, 16, 166-172. 